\title{
Representações sociais e história: referenciais teórico-metodológicos para o campo da saúde coletiva
}

\author{
Social representations and history: \\ theoretical and methodological principles \\ for public health
}

Maria Helena Cabral de Almeida Cardoso 1

Romeu Gomes 1

\footnotetext{
1 Instituto Fernandes Figueira, Fundação Oswaldo Cruz. Av. Rui Barbosa 716, 4 o andar, Rio de Janeiro, $R J$ 22250-020, Brasil. oscarmc@unisys.com.br romeu@iff.fiocruz.br
}

\begin{abstract}
This article discusses the concept of social representations on health and illness from a social/historical point of view, to provide the means for developing research in the public health care domain. To situate this discussion, the analysis was based on field research health issues, attempting to demarcate a theoretical frame of reference with the help of reference literature in sociology and cultural history, while also contemplating cultural anthropological studies conducted in the medical field.
\end{abstract}

Key words Social Representations; Theoretical Models; History; Public Health

Resumo O presente artigo tem por objetivo discutir as representações sociais de saúde e doença a partir de uma abordagem histórico-social, com vistas a subsidiar o desenvolvimento de pesquisas no terreno da saúde coletiva. Para situar essa discussão, parte-se da análise no campo da pesquisa social em saúde, como também busca-se delinear, com base na literatura, marcos teórico-conceituais de referência relacionados sobretudo à sociologia e à história cultural, embora contemplando, além disso, estudos específicos da chamada antropologia cultural relativa à área médica.

Palavras-chave Representações Sociais; Modelos Teóricos; História; Saúde Pública 


\section{Introdução}

A discussão a respeito das ambigüidades da História tem uma história sem fim. Como dar contornos definitivos a um campo do saber que se volta para o passado, a partir do presente, mas que almeja alcançar o futuro? É através do método que se deve dar estatuto científico à prática de registrar, analisar e explicar aquilo que passou, ou é pela nomeação de objetos particulares, próprios? Nesse caso, qual seria o objeto da História? Seria, como aponta Marc Bloch, "ciência dos homens no tempo" (Bloch, 1976:32)? O tempo é abstração humana; portanto, que noção de tempo está em pauta na definição de Bloch? Aquele como percebemos hoje?

Essas perguntas ilustram a multiplicidade de concepções que a ciência da História carreia. Todavia, uma assertiva comum move os historiadores de hoje: a história não é linear nem tampouco se movimenta em círculos evolutivos, ou seja, por etapas de nascimento, crescimento, apogeu e queda. Ao escrever a respeito da história, pensa-se a historicidade e, nela, os limites impostos pela maneira como os homens deram sentido ao seu viver, tentando responder de onde surgiram, quem são e para onde irão. Não é possível pensar que estes sentidos sempre foram os mesmos. A História deve buscar a compreensão de como as percepções acerca do estar no mundo mudaram e, para tanto, não tem como deixar de reconhecer que não trabalha com o estanque, pois remete-se exatamente ao mais dinâmico. Se trata dos homens organizados em sociedades, não há como negar que estuda seres que têm intenções, finalidades, escolhas, desejo, sonhos, lidando, em função disso, também com a contingência, o acaso, o cotidiano.

Dentro desse amplo espectro, a saúde e a doença consubstanciam-se enquanto "objetos" privilegiados ao esclarecimento de modos de conhecer e pensar a si próprio, aos outros e ao universo que se habita. Se há algo acerca do qual cada um tem suas experiências e costumes é o adoecimento, porque, mesmo quando se estabelece de forma aguda e passageira, coloca para todos a inevitabilidade da morte. Como bem aponta Gadamer (1996:11): “A preocupação com a própria saúde é um fenômeno que nasceu com o homem". Tal inquietação torna-se mais evidente na medida em que as biotecnociências evoluem, e a divulgação de suas aplicações pautam a possibilidade de cada um gerir seu "capital saúde" (Ruffié, 1993), tornando os homens responsáveis pelos limites do que é possível fazer diante da enfermidade e da morte.
A preocupação com as representações sociais ocupam posição periférica nos estudos históricos relacionados à área da saúde. Na realidade foi mais no campo da Psicologia, da Sociologia e da Antropologia médicas que eles se desenvolveram. Isto porque, dentro das próprias fronteiras da disciplina da História, o conceito ou o princípio metodológico de representação social, em geral, não se explicita. $O$ termo "representação", nesse caso, aparece como sinônimo de "interpretação", de "concepção" ou de "entendimento" que vários espaços/tempos históricos produziram acerca do que seria, sobretudo, a doença.

Poder-se-ia dizer que as representações, sem sequer carregarem o adjetivo “sociais", são revestidas apenas da definição mais comum encontrada nos dicionários, isto é, de sua qualificação filosófica conhecida, que as define como: "conteúdo concreto apreendido pelos sentidos, pela imaginação, pela memória ou pelo pensamento" (Ferreira, 1986:1220). Sem dúvida, esse conteúdo básico está na episteme das representações sociais, tendo em vista a correlação que faz com a capacidade possuída por qualquer homem de produzir conhecimento.

Sob a óptica das ciências sociais, todavia, a produção desse conhecimento só se concretiza como saber a partir da experiência prática da ação humana. Por isso, as representações sociais podem ser conceituadas como categorias de pensamento, ação e sentimento que expressam dada realidade, na medida em que a explicam, justificam ou questionam (Minayo, 1994).

Em História, porém, essa dimensão conceitual das representações sociais ganha contornos diferenciados, sendo sua utilização relativamente recente e remetendo-se, de início, à chamada História das Idéias, para ser instrumentalizada posteriormente por Chartier (1990) em sua proposta do que seria uma História Cultural.

\section{A história das idéias, as mentalidades e a história cultural}

Pode-se afirmar que a História das Idéias nasce de um movimento intelectual de revolta antipositivista (Hughes, 1961), reunindo: repúdio ao marxismo ortodoxo; ligação à psicanálise (a noção de inconsciente coletivo de Jung); retorno ao idealismo kantiano (e seus seguidores, como Dilthey, Rickert e Simmel); afinidade a autores como Hobbes e Maquiavel e, por fim, tentativa de superar o positivismo e o historicismo, via as proposições de Max Weber. 
O que todavia importa é apontar que as categorias teóricas fundamentais da produção dos autores ligados à História das Idéias remetiam-se prioritariamente ao papel da consciência e do inconsciente, do tempo e da duração, das particularidades das ciências humanas e dos problemas que elas traziam para a teoria geral das ciências e, por cabo, à introdução de noções tais como: "representações coletivas"; "visões de mundo"; “espírito de época”, dentre outras. Tais conceitos obviamente agenciam a noção tradicional de "idéia" como "representação mental de uma coisa concreta ou abstrata; imagem" (Ferreira, 1986:1220), encontrada em qualquer dicionário.

Rorty (1980) aponta que a instituição do Olho da Mente distinto daquele do corpo, significando o pensamento, o intelecto e a percepção, marca a separação entre os homens e as bestas, tal como assinala que esta metáfora ocular grega foi de tal maneira incorporada pelo imaginário moderno que, até hoje, é objeto de análise por parte dos filósofos preocupados com suas conseqüências, isto é, com os problemas que ela criou e com as possíveis maneiras de alterá-la. Um desses problemas é, sem dúvida, o questionamento intelectual quanto à possibilidade de conhecer o que de fato existe, tomando-se por base os dados sensíveis, instaurado por Descartes, a partir do qual a existência de dois "reais" entrou definitivamente em cena. Um "real” seria aquele percebido sensorialmente e que, por sua vez, seria somente um índice do outro "real", este, o verdadeiro, porque somente acessível ao olhar de um intérprete que conhece, que é o sujeito pensante dotado de mente e, mais importante ainda, de consciência.

Tal dicotomia, traduzível na super conhecida dualidade corpo/mente, dominou todas as formas de raciocínio, cabendo sempre à mente o reconhecimento da veracidade ou não das idéias enquanto representações reais dos fenômenos universais. Contudo, essa tradição de sempre se conceber, conforme assinala Falcon (1997:55): "significantes que remetem a significados fixos e precisos" vem sendo combatida diante dos avanços nos campos da lingüistica, da semiótica e da teoria da comunicação, dentre outros. Na historiografia, como muito bem demonstra o autor, após a contribuição dessas disciplinas, os questionamentos voltam-se para o texto e/ou discurso, para as mensagens neles contidas, mas atentos à "intertextualidade" e à "contextualidade" (Falcon, 1997:95) e, em pesquisadores que seguem os passos de Michel Foucault para "as formações discursivas possíveis no âmbito de cada 'episteme', o 'regime de tais práticas'e a 'ordem do discurso' que as caracteriza” (Falcon, 1997:95).

No entanto, existe um movimento no sentido de não reduzir as idéias a sua concepção meramente representacional, que encontra um postulante em historiadores como Véron (1977). $\mathrm{Na}$ abordagem que ele propõe, as idéias devem ser estudadas como sistema de relações, mediante a operação de descolar a noção de representação para a de operação de significação, a qual, basicamente, quer dizer um sistema de operações semânticas definidoras da recepção da mensagem pelos destinatários. Passar-se-ia, então, da noção de idéia àquela de signo, pois a idéia concebida como signo poderia sempre desempenhar várias funções.

De qualquer modo, no território da "história das idéias”, o conceito de representação liga-se à definição mais vulgarizada de representação. Tal fato, todavia, não é de causar estranheza porque, como bem assinala Veyne (1983), de há muito tempo que os historiadores, de modo geral, utilizam um grupo de conceitos que tanto se articula ao senso comum quanto às teorizações, sem se preocupar muito em dotá-los de contornos nítidos ou em discutir suas imprecisões, dificuldades e implicações.

$\mathrm{Na}$ verdade é o caráter incerto advindo do misto de ser estrutural e fatual, de querer ser objetiva e não poder sê-lo, de almejar reviver o passado e só poder reconstruí-lo, de olhar do aqui e agora para o pretérito longínquo, que tornam a História tão peculiar. Em quaisquer dos campos componentes do ofício de historiógrafo, essas clivagens e angústias permanecem, e, no seio delas, a abordagem das representações sociais acarreta o mesmo tipo de dificuldades, mesclando-se, por vezes, com uma gama de proposições nascidas exatamente do desejo de ultrapassar as ambigüidades que fundamentam a metodologia histórica.

Por exemplo, ao contrário da história das idéias, vista como historicista, a história das mentalidades teve ampla recepção por parte dos historiadores franceses que defendiam o que chamavam o "espírito dos Annales". E o que era esse espírito? Era exatamente a reunião de esforços em torno da concepção da história como ciência, pensando e nomeando suas exigências metodológicas e seu objeto, assim como sua articulação com outras ciências do homem, tais como a economia, a sociologia, a antropologia, a psicanálise, enfim, o desenvolvimento do que havia sido inaugurado por Marc Bloch, Lucien Febvre e seus discípulos desde a fundação da revista Annales d'Histoire Économique et Sociale em 1929. Após a institucionalização do grupo, em especial, na década de 
sessenta com Fernand Braudel e, na de setenta, sob a direção de Jacques Le Goff e Emmanuel Le Roy Ladurie, já na concepção de uma Nouvelle Histoire, uma "história historicizante" - a tradicional história fatual ou événementielle - pretendeu-se opor uma história nova, cujo cerne das preocupações eram "as massas anônimas, seus modos de viver, sentir, pensar" (Vainfas, 1997:130).

Não resta dúvidas de que essa perspectiva seguia os passos dos fundadores. Febvre, em particular, opunha, a uma história que se atinha somente às idéias e aceitava as obras culturais por elas mesmas - satisfazendo-se em pensar apenas em termos de suas criações, filiações e influências de estilo e corrente -, um outro programa, no qual as idéias, as obras e os comportamentos seriam recolocados no seio das condições sociais dentro das quais se haviam formatado. Sua preocupação era compreender o conjunto dos fatos culturais de uma época enquanto componentes de um reservatório complexo e dinâmico de outros fatos sociais em constante interação uns com os outros. Para ele era preciso dar conta de como, no seio da mesma cultura, havia coerência que unia a obra mais elaborada e o comportamento mais comum. Por isso, para ele, o conceito central é o de "utensilagem mental" ("outillade mental"), ou seja, o conjunto de categorias de percepção, concepção, expressão e ação que estruturam a experiência tanto individual como coletiva.

Embora fosse apressado e anacrônico, poder-se-ia ver nesse conceito, ainda parcamente explorado pela disciplina da História, uma delimitação sinônima ao que atualmente é denominado representações sociais, sobretudo na área dos estudos ligados à história das doenças. Como acentua Revel (1986), para os historiadores da história das mentalidades, ele possui conteúdo manifestamente empírico e aberto, "mas, que em todo caso vai além do que chamaríamos hoje em dia de sistemas de representações visto que inclui a língua, os afetos ou também as técnicas" (Revel, 1986:451). E não só por isso, porém, outrossim, pelo fato de Febvre nunca haver manifestado preocupação com um real passível de apreensão via representação e, sim, com a compreensão deste por meio da ciência histórica, cuja tarefa seria a de articular as manifestações de uma cultura às condições de sua possibilidade, como acesso à compreensão da unidade e da particularidade.

A força que a história das mentalidade iria adquirir a partir da década de 70, influenciando toda uma geração de historiadores, em que pese as diferenças de enfoque e propostas, marca uma espécie de retorno a Febvre. Tendo
Jacques Le Goff assumido a 6a Seção da École e André Burguière e Jacques Revel a direção da revista, o conceito de "utensilagem mental" é retomado. $\mathrm{O}$ inconsciente coletivo de Jung, tomando por base os métodos da etnografia e da psicologia, também é instrumentalizado, e a longa duração proposta por Braudel (1986) passa a ser o tempo central da análise histórica, revelando a tendência de buscar-se a permanência mais do que a mudança. A unidade, a particularidade, o cotidiano, entretanto, só ganham significação quando inseridos em totalidades explicativas que passam a ser entendidas como sistemas históricos.

Poder-se-ia, para fins meramente explicativos, dizer que, nesse momento, a história das mentalidades sublinha o superestrutural, tomando-o como eixo de investigação das diferentes ordens sociais que se engendraram ao longo do tempo. Não se trata, portanto, de proposta focal e restrita a segmentos sociais pequenos, mas sim limitada às manifestações do "espírito" que informam o "modo de vida global de um povo". Às representações sociais como vêm sendo utilizadas pela Psicologia, pela Sociologia e pela Antropologia voltadas ao estudo da saúde e da doença - a história das mentalidades contrapõe um volume abundante de objetos e abordagens. A questão das representações sociais, em caráter qualitativo ou conceitual, só ganharia contornos mais precisos a partir da "erupção" da chamada história cultural.

O que caracteriza essa nova corrente de produção historiográfica é o repúdio ao conceito de mentalidade, considerado vago, amoldável e parco para dar conta das interações entre o social e o mental. Porém, a aceitação de temas caros às mentalidades, tais como, o cotidiano, o popular, o repúdio sistemático à história das idéias, o recurso à micro-história desde que articulada a uma história global, são elementos componentes de ambas, levando corretamente autores como Vainfas (1997) a dizer que, em certo sentido, a história cultural nada mais é que novo nome para aquilo que era conhecido como história das mentalidades na década de setenta.

Uma diferença, todavia, faz-se presente e é importante ressaltá-la para os fins aqui propostos, porque talvez seja a que mais traz, para a historiografia, a problemática da representação social, dotando-a, desta vez, de contornos mais precisos. Essa diferença é a preocupação em pensar as classes sociais, o conflito, a hierarquização e a estratificação, não aceitando que as mentalidades diluam as diferenças, pois unem o conjunto social. 
Se, por um lado, o postulado da diluição é refutado, em autores como Ginzburg (1987), por intermédio da noção de "circularidade de idéias”, baseada em Mikhail Baktin, por outro, em outros historiadores, como Chartier (1990), esta dicotomia é uma falácia, uma vez que as classes só poderiam ser delimitadas no âmbito interno da produção e consumo culturais (Vainfas, 1997).

Inventariando as contribuições de autores como Febvre e seu contemporâneo Panofsky (1967), acrescidas da sociologia de Elias (1994) - em especial, as reflexões apresentadas em seu livro A sociedade dos indivíduos - e do pensamento de De Certeau (1988) acerca do ofício de escrever a História, Chartier defende a procura do social ligada às diferentes utilizações do equipamento intelectual disponível. Seu conceito de cultura é plural e ele a entende como prática, sugerindo que, para estudá-la, duas categorias são importantes: representação e apropriação.

A noção de representação defendida por Chartier (1990, 1997), conforme suas próprias palavras, relaciona-se aos trabalhos de Marin (1993) a respeito das representações de poder, articulando-se a três níveis da realidade: primeiro, ao nível das representações coletivas, que incorporam, nos indivíduos, as divisões do mundo social e organizam os esquemas de percepção pelos quais esses indivíduos classificam, julgam e agem; segundo, ao nível das formas de expressão e de estilo de identidade que os indivíduos ou grupos esperam sejam reconhecidas e, ao cabo, ao nível da delegação a representantes - indivíduos singulares, instituições ou instâncias abstratas - da coerência e da estabilidade das identidades assim afirmadas (Chartier, 1997).

Quanto à problemática da apropriação, dentro do entendimento do autor, ela tem por escopo uma história social das representações, remetidas as suas determinações fundamentais que são sempre sociais, institucionais e culturais, tal como inscritas nas práticas específicas que as produzem. Na realidade, trata-se de prestar atenção às condições e aos processos concretos determinantes das operações de produção de sentido, reconhecendo que as inteligências, em oposição ao que pensava a história das idéias, não são descarnadas, e que, ao contrário das formar de pensar postulantes de um sujeito universal, há um processo de individuação não homogêneo através dos tempos, portanto, não redutível a um eu ou a um nós contemporâneos (Chartier, 1990). Como pode ser constatado trata-se de uma epistemologia da diferença, aos moldes propostos por De
Certeau (1988), que instiga o historiador a centrar-se na análise precisa e cuidadosa das práticas pelas quais os homens e as mulheres do passado apropriaram-se, cada um de sua maneira, dos códigos e lugares sociais a eles impostos, ou subverteram-se a eles, para criar novas formalizações.

Através da implementação, na pesquisa histórica, destes dois conceitos, sobressaltando a prática em ambos, é que Chartier (1990) propugna pelo que chama de História Cultural, definindo seu objeto como "identificar o modo como em diferentes lugares e momentos uma determinada realidade social é construída, pensada, dada a ler" (Chartier, 1990:16-17).

\section{A história cultural de Chartier e os estudos relativos à saúde e doença}

Agora já se pode traçar algum paralelo, no âmbito do campo da saúde e da doença, entre tais proposições e aquelas de Herzlich (1992), uma vez que ambas objetivam a identificação das noções e valores mediante os quais os homens formam e dão sentido às suas experiências orgânicas individuais, da mesma forma que, sobre essa base, elaboram uma realidade social coletivamente compartilhada.

Em que pese as diferenças de concepção, com Herzlich (1992), assumindo mais estritamente o preceito durkheimiano de "pensamento social" e/ou "representação coletiva” e Chartier (1990), conferindo maior importância às noções de "configuração" (instrumentalizada também por Herlizch) e de "hábito social” aos moldes desenvolvidos por Elias (1994) (com base em Durkheim, mas tingido pelo pensamento freudiano), para melhor tentar equacionar a relação indivíduo/sociedade, o inegável, em ambos, é que o conceito de representação social opõe-se àquele de mentalidades exatamente por partir da diversidade, do embate e do conflito, em suma, da "epistemologia da diferença”, conforme já foi apontado.

Retomando, entretanto, o viajar pela escrita da história e a utilização das representações sociais dentro de parâmetros conceituais explícitos, cabe registrar que a proposta de Chartier (1990) encontra resistências e críticas, pois, como aponta Vainfas (1997), da maneira como é formulada, permite uma leitura que só dá sentido ao social no terreno das práticas culturais, na medida em que os grupos e as classes só adquirem identidade por via das configurações intelectuais que constróem, a partir de uma realidade sempre entendida como passível de ser analisada, pois sempre representada. 
Mas, esse tipo de crítica não é novidade nem apanágio das clivagens nos domínios da História. No terreno da Sociologia, autores do porte de Bourdieu, Paseron \& Chamboredom (1968) já assinalavam o risco de recair em um relativismo pouco producente em função de aceitar-se, sem questionamento, a validade do conceito de representações sociais, pois isso implicaria tacitamente em crer-se na transparência absoluta dos sujeitos sociais. Assim, a uma sociologia reflexiva opor-se-ia uma "sociologia espontânea”, a qual, baseada na apreensão imediata dos discursos individuais, sobreporia atitudes, opiniões, aspirações aos princípios explicativos do funcionamento de uma ordem/organização, quando o movimento contrário seria o mais producente em termos de produção sociológica.

A questão das representações sociais é bastante controversa e seu uso diversificado. Contudo, a recorrência a ela não pode ser ignorada, tendo em vista seu emprego já estabelecido por autores da psicologia social, como Moscovici (1972), da antropologia ligada ao campo da saúde (Williams, 1990; Good \& Good, 1993), da sociologia voltada às questões contemporâneas do adoecer (Herzlich, 1992; Adam \& Herzlich, 1994; Morris, 1998) e, no que tange à historiografia, de autores como Chartier que, já nas últimas duas décadas deste século, lhe aufere contornos precisos. Tanto a controvérsia quanto a diferenciação não são motivos suficientes para abandoná-las como princípio norteador das pesquisas na área das ciências sociais, mormente aquelas articuladas ao estudo das visões acerca de saúde e doença, construídas pelos homens e mulheres que vivem em um mundo cada vez mais medicalizado e, em conseqüência, no qual as biotecnociências tendem a ser valorizadas na qualidade de meio excepcional de acesso a verdade. O que cabe é proceder de maneira crítica, refletindo quanto ao conteúdo que está se dando a elas e de que maneira estão sendo instrumentalizadas.

Assim, há distinção entre as especialidades dentro da História, aqui rascunhadas, que a partir da década de sessenta referem-se às "representações" e aquela que explicita uma noção precisa, como a de História Cultural, defendida por Chartier, em que pese as críticas que lhe possam ser feitas. A segunda, tal qual as primeiras remete-se, sem dúvida, à mesma episteme que emerge no século XVII, ou seja, à noção de representação como meio de conhecimento (Foucault, 1999), só que, com base nela e em nome dela, nomeia e reivindica explicitamente os elementos e fatores específicos a serem considerados na análise, dando às re- presentações, agora adjetivadas de sociais, conteúdo de conceito metodológico novo.

\section{Concluindo}

No sentido de oferecer elementos que possam funcionar como sinais de alerta ao uso crítico e direcionado das representações sociais, visando, sobretudo, às pesquisas na área da história, sociologia e antropologia interessadas no estudo das manifestações socioculturais a respeito da saúde e da doença, elencou-se - à guisa de conclusão -, tendo por base os autores citados ao longo desse estudo que apresentam conceituação precisa de representação social, aspectos a serem tomados como princípios metódicos a qualquer trabalho que pretenda usar essa noção.

Os primeiros princípios a serem pontuados referem-se a considerações gerais e resgatam os fundamentos à instrumentalização das representações sociais em qualquer campo de estudo que se queira aplicá-las. De acordo com a revisão bibliográfica realizada, são eles:

1) as representações sociais não são o somatório das representações individuais, da mesma maneira que a representação individual não se reduz à atividade cerebral que a fundamenta. As representações sociais constituem uma realidade que se impõe ao indivíduo (Herzlich, 1991);

2) as dependências recíprocas que unem os indivíduos uns aos outros são a matriz formativa da sociedade, devendo o mundo social ser pensado como uma rede de relações. Este conceito de configuração, agregado ao de habitus, pode ser definido como "grafia social" que cada indivíduo, por mais diferente que seja do outro, compartilha com os demais membros de sua sociedade (Elias, 1994:150-151) e são chaves para não se incorrer em ligação mecânica entre uma representação coletiva e uma conduta individual específica;

3) não reduzir as práticas que constróem o mundo social à racionalidade que governa os discursos. A lógica que comanda as operações que constituem as instituições, dominações e relações não é a mesma lógica hermenêutica, logocêntrica e escritural que produz os discursos, não podendo a eles ser reduzida (Chartier, 1997);

4) as representações sociais não são apenas esforço de formulações mais ou menos coerentes de uma específica forma de saber, mas também são interpretação e questão de sentido (Herzlich, 1991);

5) os processos pelos quais os discursos soerguem interesses ou fatos são socialmente 
enraizados, determinados e limitados, de modos diversos, pela linguagem, pelos conceitos e pelos recursos materiais disponíveis a seus produtores. Assim, tais processos referem-se a propriedades sociais externas ao discurso e são características de cada grupo, comunidade e classes que compõem o mundo social (Chartier, 1997);

6) a representação social não é mero reflexo do real, mas sua construção e, nesse sentido, ultrapassa o cada um individual, chegando ao indivíduo, em parte, de fora dele (Herzlich, 1991);

7) os laços de dependência entre os indivíduos não podem ser limitados àqueles que eles nomeiam. Situações para a interação e redes de relações estão sempre vinculadas a determinações mais remotas e invisíveis que as tornam possíveis e lhes fornecem a estrutura. Isso significa que é importante tomar em conta que os indivíduos são tão aptos a ignorar os laços que os fizeram ser o que são, quanto são capazes de percebê-los (Chartier, 1997); e, finalmente,

8) as representações sociais estão enraizadas na realidade social e histórica, ao mesmo tempo em que contribuem para sua construção (Adam \& Herzlich, 1994).

No que diz respeito mais estritamente às pesquisas na área da saúde e da doença, a experiência, em particular, no campo da antropologia e da sociologia, bem como os recursos que podem ser tomados da chamada História Cultural indicam que:

1) diferentes grupos sociais experimentam concepções diversificadas relativas à etiologia das doenças, respondendo a uma lógica diferente daquela do saber médico (Williams, 1990);

2) para interpretar os fenômenos corporais, as pessoas se apoiam em noções, símbolos e esquemas de referências interiorizadas de acordo com seus meios sociais e culturais. Em casos nos quais as doenças - por exemplo, o câncer e a AIDS - estão por demais presentes no imaginário coletivo, os conjuntos de sentidos constituídos possuem força específica e se impõem principalmente aos sujeitos por elas acometidos (Adam \& Herzlich, 1994);

3) toda doença é fenômeno significativo e a atividade médica é sempre interpretativa. $\mathrm{O}$ médico interpreta os sintomas reportados por seus pacientes e os retraduz nas categorias do saber médico fundamentado pelas ciências biológicas. O doente, por sua vez, possui um ponto de vista concernente ao seu estado e forja, a esse respeito, um modelo explicativo que, embora individual em parte, está enraizado na cultura (Good \& Good, 1993);

4) a interrogação a respeito do sentido da saúde e da doença não se reduz às informações médicas. A história da medicina demonstra de que maneira as relações entre o saber médico e o senso comum podem se estabelecer nos dois sentidos, com vais e vens entre o pensamento erudito e o popular (Herzlich, 1991);

5) as representações da saúde e da doença sempre aparecem articuladas às visões que os homens e mulheres possuem do biológico e do social. A importância da doença, da saúde, do corpo, dos fenômenos biológicos enquanto objetos metafóricos e enquanto suporte do significado da relação dos indivíduos com o social vem aumentado proporcionalmente ao avanço do crescimento do papel da ciência e da técnica biomédica (Herzlich, 1991); e,

6) o modelo biomédico, tal como o raio $X$, é também, em última instância, uma representação; contudo, é tão persuasiva e poderosa que, quase sempre, todos a tomam como um fato. Todavia, não importando o quanto o fatual seja considerado, o modelo biomédico também gera uma corrente de imagens narrativas - o corpo como máquina e a doença como defeito mecânico, por exemplo - que influenciam as noções coletivas acerca da saúde e da doença (Morris, 1998).

De tudo o que foi dito, pode-se afirmar que, ao trabalhar com fontes documentais escritas ou orais, a busca das representações sociais acerca da saúde e da doença permite: (a) classificar as diferentes maneiras pelas quais os autores das fontes captam o sentido do que é ser doente e o que é ser saudável; (b) estabelecer nexos entre os diferentes tipos para que se possa chegar aos modelos sociais da saúde e doença, construídos a partir da relação espaço-tempo, dotando, portanto, tais modelos de historicidade, e (c) reconstituir, nas fontes, a lógica pela qual as representações foram produzidas e socializadas na longa duração, realizando, nesse momento, uma "decomposição", fazendo-se o "caminho de volta" para melhor compreender os antecedentes dos modelos atuais.

A referência para que se distinga o pólo social das representações do pólo individual fica por conta do que é comum nas interpretações que os autores fazem da experiência da saúde e da doença. Essas idéias que permanecem no conjunto das falas, configuradas a partir da reincidência, formam tipificação mais ampla, cujos componentes podem guardar, entre eles, relação de concordância ou de oposição. Muitas das vezes, as configurações identificadas podem constituir um mosaico com partes distintas que, ao serem "cimentadas" umas às outras, apontam contradições e/ou ambigüidades.

Saber captar qual é esse "cimento", configura, na realidade, o desafio para se chegar ao pó- 
lo das representações. Neste âmbito, o papel das disciplinas aqui evocadas, que se encontram fora do campo médico estrito senso, torna-se importante. São elas que poderão ajudar a reconhecer a natureza e os limites dessas representações com as quais a medicina, a par de seus avanços científicos, deverá lidar para melhor realizar seu trabalho de prevenção, tratamento e cura tanto de doenças milenares, que ainda vigoram, como daquelas que surgirão no futuro, talvez até favorecidas por outras inovações humanas.

\section{Referências}

ADAM, P. \& HERZLICH, C., 1994. Sociologie da la Maladie et de Médecine. Paris: Natham Université.

BLOCH, M., 1976. Introdução à História. Lisboa: Europa-América/Mem-Martins.

BOURDIEU, P.; PASSERON, J. C. \& CHAMBOREDON, J. C., 1968. Le Métier Sociologique. Paris: MoutonBordas.

BRAUDEL, F., 1986. O Mediterrâneo e o Mundo Mediterrâneo na Época de Philippe II. São Paulo: Martins Fontes.

CHARTIER, R., 1990. A História Cultural. Entre Práticas e Representações. Lisboa: Difel.

CHARTIER, R., 1997. The Edge of the Cliff. History, Language and Practices. Baltimore/London: The Johns Hopkins University Press.

DE CERTEAU, M., 1988. The Writing of History. New York: Columbia University Press.

ELIAS, N., 1994. A Sociedade dos Indivíduos. Rio de Janeiro: Jorge Zahar Editor.

FALCON, F. C., 1997. História das idéias. In: Domínios da História. Ensaios de Teoria e Metodologia (C. F. Cardoso \& R. Vainfas, org.), pp. 91-125, Rio de Janeiro: Ed. Campus.

FOUCAULT, M., 1999. As Palavras e as Coisas. São Paulo: Martins Fontes.

GADAMER, H.-G., 1996. El Estado Oculto de la Salud. Barcelona: Gedisa Editorial.

GINZBURG, C., 1987. O Queijo e os Vermes. O Cotidiano de um Moleiro Perseguido pela Inquisição. São Paulo: Companhia das Letras.

GOOD, B. \& GOOD, M. D., 1993. Learning medicine: The constructing of medical knowlegde at Havard Medical School. In: Knowlegde, Power and Practice (S. Lindenbaum \& M. Locke, eds.), pp. 81-107, Los Angeles: University of California Press.

HERZLICH, C., 1991. A problemática da representação social e sua utilidade no campo da doença. Physis, 1:22-36.
HERZLICH, C., 1992. Santé et Maladie, Analyse d'une Représation Sociale. Paris: Éditons de L'EHESS.

FERREIRA, A. B. H., 1986. Novo Dicionário da Língua Portuguesa. Rio de Janeiro: Nova Fronteira.

HUGHES, H. S., 1961. Consciousness and Society. The Reorientation of European Social Thought, 18901930. London/New York: Random House.

MARIN, L., 1993. Lire un tableua: Une lettre de Poussin en 1639. In: Practiques de la Lecture (R. Chartier, ed.), pp. 129-157, Paris: Payot \& Rivages.

MINAYO, M. C. S., 1994. O Desafio do Conhecimento: Pesquisa Qualitativa em Saúde. São Paulo: Editora Hucitec/Rio de Janeiro: ABRASCO.

MORRIS, D. B., 1998. Illness and Culture in the Postmodern Age. Berkeley/Los Angeles/London: University of California Press.

MOSCOVICI, S., 1972. Introduction à la Psychologie Sociale. Paris: Larousse.

PANOFSKY, E., 1967. Architecture Gothique et Pensée Scolastique. Paris: Minuit.

REVEL, J., 1986. Mentalitès. In: Dictionnaire des Sciences Historiques (A. Burguière, ed.), pp. 450-456, Paris: Press Universitaires de France.

RORTY, R., 1980. Philosophy and the Mirror of Nature. New Jersey: Princeton University Press.

RUFFIÉ, J., 1993. La Naissance de la Médicine Prédictive. Paris: Editions Odile Jacob.

VAINFAS, R., 1997. História das mentalidades e história cultural. In: Domínios da História. Ensaios de Teoria e Metodologia (C. F. Cardoso \& R. Vainfas, org.), pp. 127-162, Rio de Janeiro: Ed. Campus.

VÉRON, E., 1977. Ideologia, Estrutura, Comunicação. São Paulo: Martins Fontes.

VEYNE, P., 1983. Como se Escreve a História. São Paulo: Martins Fontes.

WILLIAMS, R., 1990. A Protestant Legacy: Attitudes to Death and Illness Among Older Aberdonians. Oxford: Clarendon Press. 